\title{
Sou Diáspora: Construção Social e Mobilidade através da Memória de Haitianos no Brasil $^{1}$
}

\author{
Soy Diáspora: Construcción Social y Movilidad por medio de la \\ Memoria de Haitianos em Brasil
}

\author{
I am Diaspora: Social Construction and Mobility through Memory of \\ Haitians in Brazil
}

\author{
Taíse Staudt ${ }^{2}$
}

\begin{abstract}
Resumo
O objetivo da pesquisa é a análise de lembranças de haitianos que atualmente residem no Brasil. Este trabalho é uma versão reduzida da pesquisa de conclusão de curso para graduação de História pela Universidade Federal da Fronteira Sul - Campus Chapecó. A pesquisa realiza-se a partir de entrevistas de História de Vida, dentro da metodologia de História Oral. As entrevistas foram realizadas com três imigrantes haitianos que residem no oeste de Santa Catarina, com diferenciações em gênero e idade, sendo posteriormente transcritas e transformadas em texto. A partir dos temas que se destacam nessas narrativas, são analisados alguns fatores determinantes para a formação social e cultural haitiana, da construção da característica de mobilidade e das experiências dos indivíduos na trajetória e no Brasil. Para além, são realizadas reflexões sobre o que foi dito e não dito nas narrativas e a fórmula do sucesso que envolve a saída do Haiti. Os resultados demonstram a carga da violência colonial nas experiências desses indivíduos e da estruturação de uma sociedade diáspora. Revelam a ligação indissociável da memória e da identidade com a mobilidade nas falas dos haitianos no Brasil. Espera-se que essa pesquisa coloque em evidência, com base nas histórias de vida, a experiência de mobilidade contemporânea pela visão dos indivíduos que passaram e passam por tal processo, contribuindo na redução de preconceitos e na criação de políticas públicas que facilitem a mobilidade e integração dos indivíduos.
\end{abstract}

Palavras-Chave: Construção Cultural; Diáspora; História de Vida; Mobilidade Haitiana.

\section{Resumen}

Esta pesquisa tiene el objetivo de hacer un análisis de recuerdos de haitianos que residen actualmente en Brasil. Este trabajo es una versión reducida de la pesquisa que hace parte del requisito para la conclusión de carrera en historia por la Universidade Federal da Fronteira Sul (UFFS), Campus Chapecó. La pesquisa se realiza a partir de entrevistas de historias de vida, dentro de la metodología de historia oral. Las entrevistas fueron realizadas con tres inmigrantes haitianos que residen en el oeste de Santa Catarina, con las diferencias en género y edad, posteriormente transcritas y transformadas en texto. A partir de los puntos que se destacan en esas narrativas, son analizados algunos factores determinantes para la formación social y cultural haitiana, da construcción de la característica de movilidad y de las experiencias de los individuos en esa trayectoria y en Brasil. Además, son realizadas reflexiones sobre lo que se ha dicho y no dicho en las narrativas y la receta del suceso que envuelve la salida del Haiti. Los resultados muestran el peso de la violencia colonial en las experiencias de esos individuos y de la estructuración de una sociedad diáspora. Demuestran la relación indisociable de la memoria e identidad con la movilidad en los relatos de los haitianos en Brasil. De este modo, la pesquisa es una contribución, con base en las historias de vida, que trabaja las experiencias de movilidad contemporánea vividas por los sujetos envueltos

\footnotetext{
${ }^{1}$ Artigo apresentado no Simpósio Temático Repensar, Refletir, Interpretar e Reinterpretar a Memória, Identidade e o Patrimônio Cultural na América Colonial durante o II Seminário Latino-Americano de Estudos em Cultura SEMLACult em Foz do Iguaçu/PR, Brasil, 2018.

${ }^{2}$ Graduada em Licenciatura em História; Universidade Federal da Fronteira Sul - Campus Chapecó; Chapecó, Santa Catarina, Brasil; taisesta@gmail.com
} 
en ese proceso y una forma de contribución en la disminución del prejuicio además en la creación de políticas públicas que faciliten la movilidad e integración de esos individuos.

Palabras claves: Construcción Cultural; Diáspora; Movilidad Haitiana; Recuerdos de Vida.

\begin{abstract}
The research objective is the analysis of memories of haitians, who currently live in Brazil. This paper is a reduced version of a research for an undergraduation thesis in History at Federal University of Fronteira Sul Campus Chapecó. The research is done from Life-Histories, within Oral History methodology. The interviews has been done with three haitins immigrants who live in western Santa Catarina with gender and age distinctions, been transcripted and turned into text posteriorly. From the themes that have highlighted into these narratives it's analyzed some determinant factors for Haitian social and cultural formation, on building the mobility feature and individual experiences in the trajectory and in Brazil. Furthermore, it's been done reflexions on what has been said and not been said on naratives and the formula of success that involves leaving Haiti. The results shows the load of colonial violence on experiences of these indivuals and it shows the structuring of a diaspora society. It reveals the inseparable link between the memory and identity with the mobility into Haitians' speech in Brazil. It's expected that this research highlights, based on Life-Histories, the contemporary mobility experience through induviduals vision who has gone through and goes through this process. In this way, contributing to a reduction in predujices and the creation of public politics that get easier the individuals mobility and integration.
\end{abstract}

Keywords: Cultural Constriction, Diaspora, Life-History, Haitian Mobility.

\title{
1. Introdução
}

Os estudos sobre memória, principalmente depois da Segunda Guerra Mundial, abriram possibilidades de pesquisa e têm se tornado um dos temas centrais de debate dentro da História nas últimas décadas. Para a historiografia ocidental eurocêntrica existe uma forte ligação dos estudos da memória com o tema do Holocausto, as reflexões sobre trauma, memória e história se baseiam em sua grande maioria nesse momento histórico de genocídio étnico que aconteceu na Europa.

Césaire em seu "Discurso sobre o colonialismo" (2010), coloca um contraponto no que se refere a centralidade do Holocausto, do Nazismo hitleriano, como assombroso e capaz de gerar indignação mundial. Para o autor, vale a pena estudar clinicamente esse movimento, que não se mostra imperdoável por Hitler e seu crime contra a humanidade, mas o que mais gera indignação é o fato de ter cometido tal crime contra o homem branco, humilhando o branco europeu de uma maneira que só havia ocorrido anteriormente nos processos colonialistas aos árabes argelinos, aos coolies indianos e aos negros africanos.

Falamos neste trabalho sobre memórias em mobilidade de sujeitos que carregam em si, na sua cultura, na sua negritude e na sua nacionalidade o traço da violência colonial, exercida pela ideia de superioridade europeia, assim como é marcada a população brasileira, na qual tais sujeitos convivem atualmente. A violência exercida contra a população não- 
branca - na forma de escravização de corpos, religiosidade, língua e cultura em geral - durante os séculos de expansão imperialista europeia, ainda marcam intensamente as experiências das populações colonizadas.

Este artigo é uma versão adaptada de uma monografia realizada como requisito para obtenção do grau de licenciada em História, pela Universidade Federal da Fronteira Sul, Campus Chapecó, defendida em vinte e nove de junho de 2018. Este é um estudo sobre memórias de pessoas que passaram recentemente por mudanças intensas em suas vidas: a migração do Haiti para outros países, e que, no momento, residem no Brasil, mais precisamente no oeste de Santa Catarina. Por esse fator, um dos principais interesses da pesquisa é perceber, nas memórias, características culturais da população haitiana, formada, historicamente, de migração para outros países e os resultados das dinâmicas e trocas culturais e organizacionais que tais características possibilitam, tanto para os haitianos que saem do país quanto para os que ficam.

As memórias dos migrantes instigaram atenção pelas vastas lembranças que podem ser reveladas sobre a cultura em que estavam inseridos no Haiti, os ambientes de socialização, as dificuldades, a decisão de partida, a travessia, a chegada, a nova realidade, as formações identitárias a partir da característica migrante, as experiência em outros países e, para além, as diversas lembranças que não se pode imaginar de antemão, que são únicas da experiência de vida do indivíduos. São novas experiências onde a memória pode ser instrumento de reflexão.

Optei pela pesquisa na seguinte linha: ouvir o que os haitianos tem a falar sobre si, a história e formação, ouvir as memórias desses sujeitos por sua própria voz. Pretendo que esse trabalho possa ser participativo em proporcionar reconhecimento aos sujeitos que são agentes de suas próprias histórias e fazem parte, agora, da história dos novos locais onde vivem.

Importa a esta pesquisa o contingente cultural dessa população assim como suas características formadas a partir de sua tradição migrante, que, segundo Luís F. A. Magalhães (2014), é formada desde o período colonial como consequência de fatores estruturais atualmente materializados a partir de indicadores sociais, econômicos e demográfico precários. Os elementos diaspóricos presentes nas identidades desses indivíduos, quando repensada a trajetória histórica por que passou o Haiti desde o período colonial quando colônia da coroa francesa, a diáspora forçada, as problemáticas políticas e econômicas até os recentes processos migratórios que vivem, serão pensados a partir, principalmente, de autores 
haitianos ou da região caribenha, priorizando uma perspectiva teórica que abrange de maneira mais completa a realidade investigada.

As narrativas de história de vida são o ponto de partida para os debates propostos, possibilitando analisar instrumentos de pesquisa gerados pelas lembranças. Ouvir essas experiências a partir de suas próprias percepções é um desafio e também uma abertura para conhecer espólios, características, identidades, simbolismos, dinâmicas e experiências individuais e grupais que a memória possa ser capaz de acessar.

\section{Metodologias e fontes}

De maneira breve, apresentarei as metodologias utilizadas para a realização da pesquisa, considerando que esta apresentação é importante por dois motivos principais. $\mathrm{O}$ primeiro deles é a importância da escolha da metodologia para os resultados alcançados, tanto a utilização da história de vida como método de reunir memórias e experiências quanto a utilização do referencial bibliográfico latino-americano e caribenho para realizar as reflexões. O segundo motivo se refere ao leitor: objetiva-se que todas e todos possam ler e compreender como se deram os procedimentos para que a pesquisa fosse possível, e não apenas pessoas envolvidas com o meio acadêmico ou que conheçam os métodos historiográficos de pesquisa.

Sendo assim, falar sobre memória e coletar lembranças, é (re)construir conjuntamente uma história de vida individual, com características e movimentações singulares que dizem respeito à trajetória intelectual e geográfica do próprio indivíduo. Da mesma maneira, possibilita refletir sobre outras características históricas, em diversos níveis, compreendendo que os elementos da memória dos indivíduos não estão separados das influências sociais, políticas e econômicas que os sujeitos estão atrelados.

A metodologia utilizada para a realização da pesquisa é denominada História de Vida, que é uma das possibilidades da História Oral. A história de vida consiste em realizar uma ou mais entrevistas que não possuem uma temática específica, mas pretende obter o máximo de acesso as memórias do sujeito, desde o que sabe sobre seus ancestrais e remota infância até o presente e desejos futuros. As entrevistas são geralmente mais longas que as entrevistas temáticas e necessitam de uma aproximação mais íntima entre entrevistado e entrevistador, pois revelar memórias é muitas vezes relembrar coisas negativas da sua história. A metodologia passou a ser mais aceita entre as ciências humanas com a abertura e espaço para o reconhecimento das diferenças e a "existência de múltiplas histórias, memórias e 
identidades em uma sociedade" (ALBERTI, 2011. p. 158). As entrevistas, gravadas e transcritas, são a fonte da pesquisa realizada e objetivam colocar em evidência as experiências de vida dos narradores.

Para as reflexões, foram realizadas três entrevistas de história de vida que objetivaram buscar diferentes perfis de imigrantes haitianos que possuíam certa facilidade com a língua portuguesa. Sendo assim, os entrevistados foram: Louis Sainne Bernadel, 44 anos que trabalha em um frigorífico da cidade de Xanxerê e é presidente da Associação de Haitianos de Xanxerê; Marie Merlande Divers, 27 anos, que é estudante do curso de Administração na UFFS mas atualmente se encontra fora do Brasil; e Roberson Damis, 23 anos, estudante do curso de Engenharia Ambiental (UFFS) e funcionário de uma agencia de viagens na cidade de Chapecó. $^{3}$

Opto por pensar a situação identidade e mobilidade a partir da memória de maneira que se possa também pensar a história, o trauma e a própria memória desviando da perspectiva eurocêntrica e aproximando-se das perspectivas decoloniais que visam pensar a realidade assim como a teoria epistemológica das populações colonizadas a partir delas próprias, e não continuar vislumbrando a si mesmo pelo óculos do colonizador europeu. A metodologia possibilita pensar a partir de indivíduos contemporâneos, com uma realidade de dificuldades através de problemáticas sociais atuais, ainda reflexos diretos do processo colonizador. Para tal, utilizo grande maioria de autores americanos, enfatizando caribenhos e haitianos para maior aproximação com a realidade da memória haitiana, entre eles o jamaicano Stuart Hall (2003; 2015), os martinicanos Aimé Césaire (2010) e Frantz Fanon (2008), e o haitiano Joseph Handerson (2010; 2015).

\section{Um breve histórico sobre o Haiti}

Um conjunto de processos históricos, levaram a uma configuração de constante emigração de indivíduos do seu país, Haiti. Apesar de registros informarem a presença de haitianos no Brasil desde a década de 1940, o grande fluxo dessa movimentação aconteceu a partir de 2010. Segundo dados de Joseph e Handerson (2015), eram cerca de 4 a 5 milhões de haitianos em outros países do mundo em 2015 - o que representava a metade dos habitantes estimados no Haiti no ano de 2013 - estando, desses, aproximadamente 60 a 65 mil no Brasil.

3 As entrevistas adequadas em texto estão disponíveis no item três do trabalho completo, que pode ser acessado pelo seguinte link: https://rd.uffs.edu.br/handle/prefix/2070. A referência completa está listada ao final. 
Diversos alicerces estão ancorados na atual presença haitiana no Brasil. Magalhães (2014), refletindo sobre a formação de uma tradição migrante haitiana, defende que existe um processo histórico de expulsão da população haitiana de seu país, resultado de sua posição sócio-histórica de dependência e subalternidade. Apesar de ser a colônia francesa mais próspera do mundo durante os séculos XVI e XVIII, as condições de subalternidade iniciadas com o violento processo colonial e com a estruturação e hierarquia do sistema capitalista, tornaram o Haiti o país mais pobre da América na atualidade.

Depois de largo período sob as ordens e coroa francesa, a libertação e independência haitiana acontece em consequência de uma organização e união dos negros escravizados em intenso ciclo de organização e revoltas, que se iniciaram por volta de 1789 e aconteceram até a proclamação da Independência, em janeiro de 1804. A Revolução Haitiana se caracteriza e simboliza a afronta ao regime colonial, ao racismo e a escravização de almas e de culturas no século XVIII.

Essa luta pela independência foi facilitada ou até possibilitada pela linguagem através da língua crioula haitiana, e do sincretismo religioso com o Vodu (espiritualidade e ancestralidade africana associada a alguns aspectos cristãos). Ambos os mecanismos significavam linguagem própria, demonstrando a diferença da vida escrava em relação ao mundo dos senhores brancos, agindo como possibilidade de demonstração de inquietudes que colaboraram para a revolta.

Após o processo colonial, a complexidade de instauração de uma política e economia menos dependentes dos franceses ou outras potências, se mostra dificultosa. O poder foi mantido centralizado numa minoria mulata assegurando privilégios herdados da colônia, e ainda havia a cobrança da própria França pela indenização de perda da colônia. Tais fatores e as disputas internas de poder e instabilidade econômica favoreceram a presença de potências no país, até que em 1915 os EUA passaram a controlar militarmente o país, o que perdurou até 1934 (MATIJASCIC, 2010).

Examinando a relação da história política do Haiti com a sua mobilidade, é possível visualizar um conjunto de subalternidades - classe, cor, crença, origem - que hierarquizam as populações conforme interesse do capital, decorrente do modelo econômico atual, se apropriando das mobilidades e das forças de trabalho e dominando todos os sistemas de produção e relações sociais. Tais fatores formaram os eixos de dependência do Haiti, hoje 
demonstrados em dados concretos de marginalidade e miséria, que são fatores fundamentais para compreender os processos migratórios da população haitiana:

\begin{abstract}
Analisando em perspectiva histórica, o Haiti reproduz sistematicamente fatores estruturais de expulsão de sua força de trabalho: não se trata de um país que não é capitalista, mas sim de um país capitalista dependente, que ocupa posição das mais subalternas na divisão internacional do trabalho, cujas relações de produção são incapazes de incorporar as massas haitianas à produção, ao consumo e a formas dignas de existência. (MAGALHÃES, 2014. p. 9)
\end{abstract}

A partir do terremoto ocorrido no início do ano de 2010, as condições do país e da população para manter as exigências mínimas de sobrevivência se tornaram mais complexas, gerando a necessidade de buscar de maneira urgente tais condições em outros países. A partir desses movimentos, o Brasil se torna rota mais frequente de passagem haitiana.

Durante os anos de 2012 e 2013, a região sul do país foi um dos destinos centrais dessa população. O oeste do estado de Santa Catarina, localizado no sul do Brasil e local central deste estudo, é atualmente grande centro em ascensão de atividade industrial, com a economia focada, sobretudo, no ramo de agroindústrias. No período entre 2012 e 2015, a economia brasileira fora considerada em ascensão, exigindo, em consequência, fortificação da mão de obra nas funções laborais, necessitando que as indústrias buscassem intensamente pessoas para sanar essa carência. (ANDREOLA, 2016)

A população haitiana é possuidora de uma cultura singular formada a partir de um intenso processo histórico e de subalternização que caracterizam sua cultura, memória e mobilidade. Os reflexos dessa história se entrecruzam nas narrativas de história de vida coletadas. As lembranças registradas irão nos aproximar e da realidade de ser haitiano em mobilidade no século XXI.

\title{
4. Memória e diáspora: as dinâmicas familiares e de sociabilidade no Haiti
}

Ao pensar a memória haitiana a partir das entrevistas realizadas, percebi a necessidade de refleti-las em conjunto com a característica cultural de mobilidade e hibridismo presente nos indivíduos. As lembranças narradas, carregam constantemente e de maneira indivisível traços que refletem a diáspora haitiana em condições cotidianas, dentro do contexto familiar, local, escolar até o presente.

As falas do narrador Roberson, por exemplo, quando relembra sua infância ou momento que mais marcaram este período de sua vida, as lembranças são associadas 
diretamente ao seu pai e aos poucos momentos que passou com enquanto era criança, já que seu pai estava em mobilidade desde o nascimento de Roberson, trabalhando em Bahamas. De maneira muito interessante as falas dos outros narradores, Bernadel e Marie, também associam todas as etapas de suas vidas com situações de mobilidade, suas próprias ou de membros da família.

Quando se fala em mobilidade, ela não significa necessariamente momento emigratórios e imigratórios em âmbito internacional, mas também movimentações dentro do próprio país em busca de melhores condições de vida, ou até as dinâmicas de mobilidade entre casas de familiares, como forma de organização. Desta forma, a mobilidade se coloca como parte estruturante das formas de vida e cotidiano de grande parte da população haitiana. (HANDERSON, 2015).

Todos os relatos demonstram que os narradores conheceram a mobilidade, dentro do núcleo familiar, já durante a infância com a saída de membros do país ou de sua cidade, em busca de melhores condições. A fanmi é geralmente o local central de inserção na mobilidade e dela que parte a necessidade de saída.

As condições citadas anteriormente que geram a necessidade de mobilidade haitiana na atualidade atingem de maneira inicial esse núcleo: as famílias, responsáveis pela inserção social e pela manutenção das condições de vida, não conseguem manter economicamente, por falta de emprego e políticas sociais, essa sustentação. A necessidade primária, principalmente de alimentação e financiamento dos estudos, aparecem como objetivos finais do salário dos haitianos que vivem no Brasil.

A importância do papel familiar na mobilidade é expressa nas falas dos entrevistados em diversos momentos, como motivação central de saída do país e também motivação e força para ultrapassar as dificuldades. Roberson comenta diversas vezes sobre realizações de reuniões com seus pais para decidir a situação de sua saída do país e como eram pensadas coletivamente tais procedimentos, como financiamento e destino.

Dessa maneira, existe uma relação muito próxima entre os escolhidos a partir e aqueles que ficam, pois aquele que migra, escolhido pela fanmi, parte com a responsabilidade de trazer os retornos aguardados por aqueles que ficam. Os critérios de escolha não são iguais ou pré-definidos, mas planejados através das possibilidades, ajustando as relações internas da família através das dinâmicas de circulação. (HANDERSON, 2015) 
Esses indivíduos partem com a possibilidade do que Bernadel cita diversas vezes: "tem que ajudar a família". A família, parte do processo migrante, aguarda o retorno da empreitada no exterior para suprir, geralmente, as necessidades básicas. Segundo Handerson (2015), é negado a esse escolhido para viajar, a possibilidade de não obter sucesso financeiro na viagem. São sua responsabilidade a manutenção da escola, dos rituais religiosos (roupas para a primeira comunhão), rituais de morte (velórios), entre outros. Para além da manutenção e ajuda familiar, o envio de dinheiro ao Haiti simboliza que esse sucesso está sendo alcançado e a legitimação total está no ato de "mandar buscar" outro familiar que ficou no Haiti.

\begin{abstract}
As expressões haitianas, chèche lavi miyò (tentar uma vida melhor), chèche lavi lòt bò dlo (tentar a vida além do mar), chèche lavi aletranje (tentar a vida no exterior)(...) essa busca não se resume apenas à pessoa que viaja, mas também aos familiares que ficam é a busca de uma melhor condição de vida, um melhor salário para garantir à família, um melhor nível de educação, sobretudo, uma moradia digna que se concretiza através da construção de uma casa no Haiti. (HANDERSON, 2015. p. 182)
\end{abstract}

As lembranças demonstram, a partir disso, que a mobilidade e a família, além de centrais na memória, possuem uma dinâmica coletiva, que não pode ser desvencilhada, mas ela é por conseguinte, completa.

Além do fator da importância da família, um tema quanto às experiências narradas por Roberson que se mostrou central foi a centralidade das casas (kay em crioulo), de sua construção e do caráter e status social que ela representa. Roberson (2018) nos diz que "lá [no Haiti], quando você tem um monte de bens você é rico. Você não tem dinheiro guardado, mas se você tem bastante casas ou terrenos enormes, você é rico". A mesma seguridade é solicitada quando haitianos resolvem casar e formar famílias, como relata Roberson: "A questão de casamento lá é também, como posso dizer, uma coisa gigantesca. Pra eles é muito, porque pra casar, lá, você tem que ter tudo. Quando falo tudo, você tem que ter pelo menos uma casa" (DAMIS, 2018). O narrador também cita fortes regramentos religiosos e familiares quanto a relacionamentos e práticas sexuais, demonstrando uma cobrança extrema para que não tenham relações antes de casar e estarem com uma certa estabilidade financeira. Para o narrador, não se pode ancorar estas práticas sociais apenas em alicerces culturais ou influências religiosas, mas algumas práticas são consequência de estruturação econômica, política e social de muitos anos, obrigando a população a se adequar as maneiras e modelos de vida possíveis, assim como se adequou e incorporou a mobilidade:

Não é uma questão somente da cultura, é uma questão de preparação também. Imagina só, o cara com 15 anos ter um filho... Aqui no Brasil não é nada, mas lá no 
Haiti é muito, porque lá o cara tá com 28 anos, não consegue trabalhar... Imagina o cara com 15. (DAMIS, 2018)

\subsection{Sociabilidade e inserção social no Haiti}

A infância e adolescência: o local de convivência e da formação identitária, de se conhecer e conhecer aquilo que faz parte de si, a introdução e a socialização. Todo esse momento da vida do indivíduo é reativada, ou melhor, (re)inventada, durante uma entrevista de história de vida. Os narradores viveram e formaram essas características no Haiti, em regiões distintas, no entanto, carregam traços singulares que nos aproximam um pouco mais de como é, ou como foi para Roberson, Marie e Bernadel, a socialização e formação nos espaços pessoais - principalmente em suas casa - ou sociais, caracterizado principalmente pelo papel escolar no seu país de origem. Perante as singularidades das experiências dos indivíduos e inúmeras possibilidades de temáticas possíveis de análise a partir das falas, necessitei limitar alguns temas que se tornaram centrais dentro das narrativas quanto as experiências e formações sociais no Haiti.

Considerando o limite de discussões possíveis neste artigo que resume um estudo maior, irei debater aqui quatro questões que se mostraram centrais nas narrativas dos entrevistados: a centralidade da família, que se mostrou o grande alicerce de toda a sociabilidade e inserção social haitiana; a escola, que manifestou-se o local de maior inserção social fora do ambiente familiar e também evidenciou diversas relações de poder instituídas, a língua crioula, seus usos, restrições e importância para a cultura haitiana; e ainda a religiosidade Vodu, que não foi citada diretamente pelos entrevistados, mas que as entrelinhas revelam relações de silenciamento alicerçadas na violência colonial.

Tanto as memórias de história de vida dos entrevistados, quanto o material bibliográfico e literatura haitiana, colocam em evidência o local e importância da família para a formação social haitiana, a maneira como ela localiza e estrutura as identidades coletivas e individuais. Por esses fatores e pelo destaque dado a essa instituição nas lembranças dos entrevistados, considerei necessário compreender a maneira como a família ou os outros laços afetivos influenciam na formação social e na mobilidade dos haitianos. Como na já citada fala de Roberson "família é primeiro lugar". Nas memórias narradas, o papel familiar e a sua dinâmica e identidade é o fator principal de inserção na sociedade e na própria mobilidade.

O histórico familiar, os antepassados e a identidade familiar manifestam ser muito respeitadas, como primordial, aquilo a que se deve sacrifícios. Para Roberson (2017): "agora o meu maior objetivo é o quê? Primeira coisa é família, sempre vai ser, e depois é estudo...”. 
Na fala de Bernadel, já citada, ele ressalta que "não tem essa sorte pra viver com a família, certinho", lamentando a maneira com que viveu e vive distante de toda a sua família, inclusive tios e outros que nunca conheceu. A família é colocada também num papel central em sua fala, porém, a necessidade da mobilidade e as questões sociais, impedem Bernadel de conhecer e viver com seu núcleo familiar quando criança e jovem. No entanto, quando fala dos motivos de sua mobilidade atual, cita, assim como Roberson que é para ajudar a família. As oportunidades que Bernadel não teve por viver sozinho a maior parte de sua juventude, a distância da família, aparecem como motivações para não ficar distante da família que formou com sua esposa e filho. Ele relata a dificuldade de deixar os dois no Haiti, buscar uma vida fora do país, sem saber ao certo onde iria. Mas um ano depois de se estabelecer em Xanxerê e conseguir emprego, conseguiu juntar o dinheiro suficiente para que sua família também viesse.

Ao pensar a questão familiar a partir da violência do sistema colonial, uma das coisas que foi negada aos negros escravizados na América, era o direito à memória e a família, os laços afetivos e sentimentais. A importância da família nos alicerces atuais no Haiti podem atuar como contraponto aos laços retirados a partir da crueldade colonial, pois:

Com estratégica crueldade e rude pretensão, procurava-se condenar o negro à dúvida da origem, assim como à ignorância do ponto de chegada, buscando fazer do escravo uma tabula rasa. Um ser sem memória, sem afetividade, sem laços de família, sem vínculos de pertencimento, sem história a ser partilhada. Eis o projeto escravagista em sua face cruel, pois significava negar ao escravo a sua humanidade. (HANDERSON, 2010. p. 72)

Essa negação efetuada durante tanto tempo no projeto colonizador, que objetivava a retirada dos enlaces sentimentais que caracterizam, assim como a religião e a língua, sua tradição, memória e humanidade, podem ter sido convertidas na atual posição da família e dos laços sentimentais, afirmando assim sua ancestralidade e humanidade por tanto tempo violentadas. Abrangendo essa discussão, Frantz Fanon destaca a necessidade de demonstração dessas características em contraponto ao que o branco colonizador impõe, quando diz que:

No caso do negro, nada é parecido. Ele não tem cultura, não tem civilização, nem "um longo passado histórico". Provavelmente aqui está a origem dos esforços dos negros contemporâneos em provar ao mundo branco, custe o que custar, a existência de uma civilização negra. (FANON, 2008, p. 46)

As condições citadas anteriormente que geram a necessidade de mobilidade haitiana na atualidade atingem de maneira inicial esse núcleo: as famílias, responsáveis pela inserção 
social e pela manutenção das condições de vida, não conseguem manter economicamente, por falta de emprego e políticas sociais, essa sustentação. A necessidade primária, principalmente de alimentação e financiamento dos estudos, aparecem como objetivos finais do salário dos haitianos que vivem no Brasil. Dessa maneira, a família é centralidade na fala dos entrevistados do início ao fim como a base sentimental e social dos sujeitos.

Quanto a introdução no meio social dos indivíduos, as histórias de vida possibilitaram perceber que o maior contato social se dá, fora da casas e da família, nas instituições escolares. Os relatos, com exceção do de Marie, trazem poucas socializações externas ao ambiente escolar, como encontros e brincadeiras com amigos em ruas ou praças. A escola é central quando se fala da infância e da adolescência, o local de experiências e inserção social.

Entre os entrevistados, todos tiveram oportunidade de frequentar regularmente uma escola no Haiti, pública ou paga, realizando toda a formação básica. Dois deles, Bernadel e Marie, iniciaram um curso de ensino superior no próprio Haiti. Isso nos revela algumas características sociais dos entrevistando, quando se considera que as condições para realização dos estudos no país não são consideradas funções do Estado, voltados quase totalmente para iniciativa privada, sem efetivação de políticas de inclusão das crianças e adolescentes na educação básica.

É importante ressaltar que 50\% das crianças haitianas estão fora da escola e, entre as que estão dentro, mais de $80 \%$ frequentam escolas privadas. Nessas, a prática de "seleção por eliminação" vem afastando centenas de milhares de jovens do ensino médio e superior. (MARQUES, 2012. p.106)

Marques (2012) teme que o sistema de ensino haitiano reproduza uma estrutura baseada na exclusão, garantindo ensino e aprendizado, que são essenciais para o alcance de condições de trabalho no Haiti, apenas para a elite econômica. As falas dos entrevistados refletem essa busca e dificuldade que se mostra o estudo para as famílias em situação econômica menos favorecida. Bernadel cita diversas vezes que "tem que batalhar pra estudar", enquanto relata as dificuldades enfrentadas por sua mãe, para conseguir mantê-lo na escola.

Quanto o ambiente escolar como local de formação identitária do indivíduos, se destacaram alguns aspectos citados pelos entrevistados quanto a comportamentos e regras que as instituições, voltadas aos padrões e normas eurocêntricas. Marie cita que uma das lembranças que lhe surgem quando lembra a época da escola, é a vestimenta obrigatória de uniforme com saia abaixo do joelho e a maneira que as meninas tinham que usar o cabelo 
preso, não podendo deixar os cachos soltos (já que a maioria da população possui cabelos cacheados) e nem fazer as tranças no estilo nagô. Com a população negra e característica de cabelos crespos e a cultura das tranças nagô, a negação dessas expressões corporais culturais na escola, demonstram uma negação aos traços culturais afro presente nas estudantes. Para além, são citadas pelo entrevistados as questões das escolas católicas, das escolas divididas por gênero e da diferenciação de conteúdos ministrados aos meninos e as meninas.

Dessa forma, a escola se mostra como um local divisor e marcador de status e classe social: aqueles que estudam representam a parcela que, mesmo com dificuldade, encontra meios de frequentar, e aqueles que não alcançam a oportunidade pelos espaços econômicos e sociais que ocupam.

Durante as falas em relação a escola, outra questão muito interessante foi citada por todos os entrevistados: é proibido falar crioulo haitiano na escola. A língua crioula, que possui importante papel na história e cultura haitiana, sendo juntamente com a religiosidade Vodu instrumento que possibilitou a revolução contra o sistema colonial, é a linguagem falada por toda a população, ensinada e repassada geracionalmente. No entanto, nos espaços de formalidade a língua utilizada é a língua francesa, instituída a partir da colonização. Na escola, por exemplo, os narradores comentam que é somente é permitido dialogar em francês, língua que também é utilizada pelos professores e pelo livro didático. Marie e Roberson comentam até de certos castigos psicológicos e físicos para aqueles que utilizarem a língua crioula em sala de aula.

O crioulo é a linguagem popular, falada por praticamente toda a população. Bernadel (2018) expõe: "Na rua tudo bem, porque todo mundo tem um conhecimento bem diferente. Não dá pra chegar e falar francês com ninguém, não, tem que chegar e falar crioulo, porque o povo, o idioma dele é crioulo." Dessa maneira, as expressões cotidianas da grande massa populacional haitiana é feita através dessa linguagem, mas as relações realizadas formalmente, geralmente acontecem em francês.

Fanon, em sua obra "Peles Negras, Máscaras Brancas" (2008), trabalha de maneira específica a questão das populações negras que passaram pelo processo de colonização e sua utilização das linguagens. Fanon (2008, p. 42) destaca que nas Antilhas "os professores vigiam de perto as crianças para que a língua crioula não seja utilizada", e tudo isso estaria ancorado no violento e desumanizador processo colonizador. Para Fanon, falar o francês aproxima o negro antilhano do branco, se aproximando consequentemente, da humanidade, 
aumentando suas possibilidades de atitude, abrir portas que foram fechadas por muito tempo. Ou seja:

Todo povo colonizado - isto é, todo povo no seio do qual nasceu um complexo de inferioridade devido ao sepultamento de sua originalidade cultural - toma posição diante da linguagem da nação civilizadora, isto é, da cultura metropolitana. (FANON, 2008. p. 34)

Da mesma maneira que é possível perceber por esta leitura o peso da violência colonial e pós-colonial nos usos das linguagens, ela pode ser percebida nas expressões de religiosidade Vodu dos entrevistados. Diferentemente da língua, o Vodu não é citado pelos narradores, a não ser quando questionados, e o fato de não ser citado também é motivo para análise.

A religiosidade Vodu se mostra, assim como o crioulo, um elemento essencial quando se pensa no processo histórico de formação cultural haitiana, ou até mesmo o principal elo para revolução que alcançaria a primeira república negra na América. Dany Laferrière, escritor haitiano, em seu livro "País sem Chapéu", ressalta como até a atualidade, as crenças e rituais Vodu se fazem presentes de maneira constante no dia-a-dia dos haitianos, principalmente nas camadas menos abastadas da população.

As fala dos narradores demonstra que existe um preconceito no próprio Haiti com a religiosidade Vodu:

\footnotetext{
é que tem muito preconceito assim... porque a religião principal do Haiti seria o Vodu, que é tipo macumba, só que quando você pratica esse tipo de religião tem muito preconceito, aí quando você tá praticando, você pratica escondido, entendeu? (...) Eu não sei ninguém da minha família que tenha praticado, até porque quando eu tava crescendo a mãe, a vó, me ensinavam a não praticar, falavam que não era pra praticar porque quando você vai lá você tem tendência a fazer mal pras pessoas e não é pra mim ir, essas coisas. (...) Isso não quer dizer que a mãe nunca foi, talvez ela foi, escondido. (DIVERS, 2018)
}

A fala de Marie demonstra que o preconceito ao voduísmo é temido no Haiti, e no Brasil ele também acontece pois aqueles que praticavam vodu, geralmente receiam se identificar como praticantes, principalmente devido aos estigmas que relacionam vodu com superstições (HANDERSON, 2015). Dessa forma, não falar sobre o voduísmo de maneira aberta e próxima, como aconteceu nas entrevistas, pode estar relacionado a alguns fatores: ou os entrevistados não possuem nenhuma proximidade com as práticas Vodu, ou, falar sobre o voduísmo para alguém que não é do universo haitianos - entrevistadora - pode ser uma tarefa complexa e também desconfortável pelos estigmas relacionados à religião. 
A prática, proibida até a legislação de 1987 e regularizada no decreto de 2003 do Haiti, é considerada religião. "Com o Decreto, na verdade, é como se estivéssemos finalmente diante de uma verdadeira ruptura com mais de dois séculos de marginalização do Vodu" (PIERRE, 2009. p.105). O "não-dito" demonstrado pelas narrativas de histórias de vida, perante o Vodu, pode então representar muito e ser analisado sobre a formação cultural haitiana, assim como tudo o que é - ou pode ser - dito.

\title{
4.2 A mobilidade: trajetória e integração
}

A formação de cultura e identidades em movimento, característica dos haitianos como vimos nas reflexões realizadas até o momento, carrega traços formados por diversas gerações que realizam na movimentação sua formação e organização social. Stuart Hall (2003) demonstra como essas movimentações haitianas se assemelham a de outros países caribenhos e de que maneira essas trajetórias estão ancoradas em sua identidade e historicidade cultural formada a partir da violência colonial estabelecida nesses territórios:

\begin{abstract}
Nossas sociedades [caribenhas] são compostas não de um, mas de muitos povos. Suas origens não são únicas, mas diversas. Aqueles aos quais originalmente a terra pertencia, em geral, pereceram há muito tempo - dizimados pelo trabalho pesado e a doença. A terra não pode ser "sagrada", pois foi "violada" — não vazia, mas esvaziada. Todos que estão aqui pertenciam originalmente a outro lugar. Longe de constituir uma continuidade com os nossos passados, nossa relação com essa história está marcada pelas rupturas mais aterradoras, violentas e abruptas. Em vez de um pacto de associação civil lentamente desenvolvido, tão central ao discurso liberal da modernidade ocidental, nossa "associação civil" foi inaugurada por um ato de vontade imperial. O que denominamos Caribe renasceu de dentro da violência e através dela. A via para a nossa modernidade está marcada pela conquista, expropriação, genocídio, escravidão, pelo sistema de engenho e pela longa tutela da dependência 'colonial. (HALL, 2003. p.30)
\end{abstract}

Diretamente relacionado com o "status social” possibilitado pela diáspora, é possível perceber a importância dessa possibilidade - migrar - para a comunidade haitiana, como alternativa de uma melhoria de vida. A mobilidade significa então, a possibilidade de encontrar aquilo que o Haiti, a partir de seu histórico político e econômico, não pode oferecer a toda a população.

O mundo da mobilidade possui lógicas próprias que ordenam a vida das pessoas e o seu mundo social. A mobilidade se desenvolve, ao mesmo tempo, como uma perspectiva econômica, mas também como um modelo social. De prática conjuntural, a mobilidade tende a se constituir, a partir de uma lógica estrutural. No Haiti, ela se impõe como uma realidade social de primeira ordem. (HANDERSON, 2015. p. 187) 
A relação da obrigatoriedade da mobilidade, de ser diáspora, se coloca em diversos momentos históricos no país por diversas condições se torna um objetivo de vida, um sonho, pelo papel estrutural, pelo retorno e imaginário criado na sociedade haitiana.

As rotas realizadas pelos narradores tiveram suas singularidades: umas planejadas, outras de "surpresa"; algumas com visto prévio para entrar no Brasil, outra sem, mudando muitas das dinâmicas de viagem; algumas com destino certo e outras buscando as melhores possibilidades durante a movimentação ${ }^{4}$. Apesar de muitas possibilidades de destino, de vários países pelo caminho, o Brasil foi a escolha dos três entrevistados e eles citam, de forma diferente, o mesmo motivo: a abertura do país em questões burocráticas após o terremoto de 2010. A facilitação da realização da documentação a partir da Resolução no 97 de 12 de janeiro de 2012, do Conselho Nacional de Imigração, assim como a abertura das Universidades brasileiras com vagas direcionadas aos imigrantes haitianos foram motivações importantes na decisão de vir ao Brasil.

No entanto, o imaginário criado sobre o Brasil não correspondeu por completo com a realidade encontrada, principalmente quando Roberson, Marie e Bernadel chegaram no sul do Brasil. Roberson não acreditava que o Brasil seria um país preconceituoso pela multiplicidade cultural que ele via, através da mídia, antes de chegar. Não aparecem referências diretas a situações que o narrador tenha sido alvo de algum tipo de racismo no Brasil, mas ter citado o preconceito, demonstra que conhece situações desse cunho. A fala de Marie, nos leva a outra dimensão desse caráter, sendo que em sua narrativa, ela demonstra como sofreu diversas situações de xenofobia, racismo e de machismo na cidade de Chapecó. Ambos citam que o que conheciam a partir da mídia, o Brasil demonstrava ser muito diferente. O estranhamento dos brasileiros à presença haitiana- aparece diretamente na fala ou nas entrelinhas das narrativas, evidenciando a conduta da maioria dos brasileiros, no oeste catarinense, em diferenciar o imigrante daquele que nasceu na região.

O Brasil é reconhecido, a contragosto de alguns, como miscigenado a partir da década de 1930: a criação das primeiras universidades demonstra a fragilidade dos institutos e a decadência teórica do evolucionismo social que idealizada e sustentava a ideia de embranquecimento do Brasil (SCHWARCZ, 1993). O oeste catarinense, no entanto, assume um contraponto quanto a idealização de hegemonia nacional por ter um processo de

\footnotetext{
4 Os mapas das rotas dos narradores e maiores informações sobre a trajetória se encontram no trabalho completo. Referência completa listada ao final.
} 
colonização tardio, uma dinâmica econômica que não foi inserida no modelo colonial de grandes plantações, se voltado para a pequena propriedade e agricultura familiar e uma economia regional, diferenciada também pelas características da população que habitou os espaços. (SOARES; ANDREOLA 2017) As terras da região oeste catarinense foram vendidas apenas para descendentes diretos de imigrantes, geralmente alemães e italianos, justamente com a ideia de transformar a região num espaço de população branca com cultura eurocêntrica.

Compreendo que a região oeste é, dessa forma, uma região com característica de imigração. No entanto, apesar do número de haitianos no Brasil ser muito inferior a diversos outros grupos que imigram, a presença haitiana gera um impacto diferenciado quando se refere ao oeste catarinense: a negritude presente em seus corpos revela o impacto com uma estrutura de poder baseada na perpetuação da hegemonia branca instaurada com os ideais europeus (SOARES; ANDREOLA, 2017). A presença haitiana é para os brasileiros da região, a configuração daquilo que é diferente de si, a característica e identidade que não é sua, é o outro, como demonstra a situação que Marie nos revela:

Teve uma vez que eu fui no Brasão Avenida, eu cheguei pra pagar as minhas compras, a moça que tava no caixa falou, ficou olhando pra mim assim e falou pra outra moça: "Vem aqui, vem aqui ver, olha que linda. Posso tocar no seu rosto?". Eu olhei pro meu amigo e ele falou: "Ela falou pra você se ela pode tocar no seu rosto". Aí eu falei: "mas por quê?". Ele falou: "Você quer ou não?". Eu falei: "Ela pode". Aí ela tocou: "meu deus do céu, que macia, vem aqui tocar o rosto dela". Tipo... Eu fiquei: “O que que é isso, gente?”. (DIVERS, 2018)

O processo tardio desta habitação reflete nas formações identitárias e de poder regionais que podem ser percebidas em alguns relatos dos entrevistados, mas principalmente da entrevistada Marie, que sofre para além das expressões de xenofobia e racismo, o preso da estrutura patriarcal e machista nas suas relações. No vídeo em que Marie participou, realizado e publicado pelo NEABI da UFFS- Campus Chapecó, a entrevistada relata, além de situações de racismo vividas dentro da universidade, as dificuldades que teve quando em busca de trabalho na cidade de Chapecó, de visitar e realizar entrevistas entrevistas em locais que negavam - mesmo com a oferta de vaga exposta - que necessitavam de funcionários. Cita ainda uma situação específica em que vai a um local em busca de emprego e deixa o telefone. O funcionário ou dono da empresa a segue na rua assim que sai do local, dizendo que pode ajudar e arrumar um emprego pra ela, mas antes ela teria que viajar com ele, entre outras coisas. Nas palavras de Marie no vídeo: 
A pessoa não, não fala com você, não fala "qual o seu nome? O que você tá fazendo da vida? O que você quer da vida?" não quer saber isso. A pessoa só vê em você uma mulher preta que, que com certeza pobre, porque não tem como você ser preta e rica ao mesmo tempo, ainda pior quando você é haitiana! Tipo você chegou aqui a pessoa começa a "ah, ela não tem dinheiro, ela não tem nada, daí eu vou oferecer dinheiro pra ela e ela vai me oferecer o corpo dela, é a única coisa que ela tem". 5

A socialização nesse processo diaspórico se mostra como um desafio diário quanto a chegada de homens e mulheres haitianas no Brasil e se torna mais complexo quando se analisa que todo esse processo se deu, em uma língua que era desconhecida, de maneira total, para a maioria dos imigrantes que chegam ao país.

Importa ressaltar que a linguagem ultrapassa toda a pesquisa pela característica e diferenciador cultural que ela carrega, e especificamente no caso pesquisado, é elemento fundamental para compreender um processo identitário e de integração dos indivíduos. Todos os entrevistados conseguem se expressar de maneira razoavelmente boa em português, mas esse detalhe também é interessante ser analisado: muitos haitianos que residem na região a alguns anos, ainda não falam ou se expressam na língua portuguesa, e essa estatística se dá principalmente nas mulheres, a partir do que pôde ser observado nas conversas informais na universidade, outros locais de socialização e a partir do trabalho de pesquisa realizado. Sobre o assunto da língua entre as mulheres haitianas, Marie nos diz que:

Primeiramente eu acho que é por causa da timidez. Em segundo lugar, eu acho que tem o machismo também, tem um monte de mulheres haitianas que tem marido. Aí o marido pressiona a mulher, fala que "não é pra você conversar com ninguém". Quando você vai fazer alguma coisa junto contigo, o homem vai lá e aprende falar português e ele vai lá falar com as pessoas. Quando a mulher quer alguma coisa, ele que vai lá também pedir, porque ele quer saber tudo da vida da mulher, aí a mulher fica na dela, não quer se relacionar, não quer aprender porque o marido vai ajudar, o marido vai fazer o seguinte, o marido vai... Mas não é bem que ele vai ajudar, é machismo mesmo. O homem acha que ele é superior, que ele que tem que fazer tudo, que ele tem que ter o poder. (DIVERS, 2018)

Observo assim, que para além das dificuldades enfrentadas pelas mulheres haitianas, por serem imigrantes com a negritude presente em sua pele, elas enfrentam essa dificuldade estrutural, patriarcal, marcada de forma intensa pela língua e por outro fatores que envolvem o fato de serem mulheres negras: as vagas de emprego ofertadas para elas, no Brasil e outros países, são as principais dificuldades que elas enfrentam.

5 SER imigrante e negra no sul do Brasil.. Direção de Gerliane Mendes. Chapecó: Neabi: Núcleo de Estudos Afrobrasileiros e Indígenas, 2017. Son., color. Disponível em:

<https://www.youtube.com/watch?v=3bDrSEZgtvw\&t=297s >. Acesso em: 9 mar. 2018. 
É possível perceber nas narrativas muito apreço ao governo brasileiro pelas oportunidades de mobilidade, de estudo e de trabalho quando as condições de seu país de origem não pode oferecer. No entanto, de maneiras diversas, é possível perceber como algumas formas de relações de poder estabelecidas historicamente principalmente na região onde estes haitianos vivem atualmente, dificultam alguns processos de integração e sociabilidade dos mesmos com os brasileiros. Os marcadores linguísticos quanto ao diferencial de gênero, demonstram na linguagem, que é local social de poder (COSTA, 2016), que na estrutura social as mulheres haitianas permanecem em uma esfera ainda mais distante da sociabilidade e integração no Brasil. Com a dificuldade de emprego para as mulheres, que tenham um retorno mediano ou bom no salário, fica evidentemente mais distante o alcance do sucesso da empreitada, as mulheres relatam muitas dificuldade de enviar as remessas de dinheiro necessárias para o sustento da família que ficou no Haiti e a tristeza de não alcançar, nem de perto, o sucesso planejado com a mobilidade.

Por fim, a mobilidade se coloca como constante nas falas dos narradores. O Brasil não é um destino final, mas é um lugar de trânsito, um local momentâneo para se alcançar melhores condições de vida. Os planejamentos futuros de Bernadel, Marie e Roberson são destoantes, cada um planeja seguir algum caminho, mas os sonhos de todos eles está relacionado com mobilidades, seja de volta para o Haiti, seja para qualquer lugar do mundo.

\section{Conclusões}

As questões ligadas a presença haitiana no Brasil e na região, puderam ser analisadas em profundidade com base nas histórias de vida que revelam, juntamente com as análises bibliográficas, a formação de um tradição migrante (termo utilizado por Magalhães (2014) e a construção histórica política, econômica e social do Haiti, possibilitando um conhecimento aprofundado no que se refere ao fenômeno de presença massiva de haitianos no Brasil.

É essencial pensar a presença haitiana no Brasil a partir do Haiti e dos haitianos, e não ao contrário. Apesar da presença brasileira no Haiti no século XXI e do aquecimento da economia brasileira no início da presente década, investigar a vinda de haitianos para o Brasil através da inversão, demonstrou que a mobilidade está historicamente ancorada na identidade cultural haitiana e que ela se coloca como necessidade estrutural dentro de uma realidade de subalternizações acumuladas. Em relação ao Brasil estar, nesse momento, entre os países que 
os haitianos buscam, ficou evidenciada a opção dos narradores pela facilitação na legalização da presença dos haitianos no país, após o terremoto de 2010.

Observo alguns aspectos que correspondem a formação social e cultural haitiana que mais se destacaram considerando as histórias de vida e leituras relacionadas. Foi possível revelar a estreita ligação entre a identidade e a mobilidade nas memórias dos haitianos entrevistados, assim como a importância e centralidade familiar em todos os períodos da vida, exercendo um papel central nas motivações e colaborações para a mobilidade. Priorizei destacar elementos que se demonstraram centrais nas características sociais do Haiti, abordando a centralidade da língua crioula haitiana como marca de quebra dos alicerces coloniais e sua proibição nos espaços escolares, e também, as possíveis motivações para ser pouco citada nas narrativas a religiosidade Vodu, também elementar quanto a história de revolução haitiana mas estigmatizada e ligada a atividades negativas.

Considerei necessária uma abordagem quanto as dinâmicas de mobilidade haitiana, o histórico de fluxos migratórios e o ideal de sucesso profissional e financeiro que envolve, no imaginário haitiano, a emigração do Haiti, geralmente para grandes potências econômicas. Da mesma forma, foi possível elucidar sobre as utilizações do termo diáspora no campo teórico e seu uso social no Haiti, que simboliza sujeitos em mobilidade e alcançando o sucesso, que retornam momentaneamente para o país de origem, assim como os objetos relacionados com os sujeitos diáspora.

Explorei também as trajetórias realizadas pelos entrevistados, os processos de socialização e integração na região em que residem os casos racismo e xenofobia, centralizando a experiência e dificuldades enfrentadas pelas mulheres haitianas que enfrentam dificuldades frequentes pelas opressões machistas, racistas e xenofóbicas estruturadas.

Dessa maneira, se evidencia esta pesquisa no campo historiográfico do tempo presente, que pela proximidade com a memória, a literatura e outras ciências sociais e humanas como a sociologia, antropologia e a linguística, é capaz de refletir sobre fenômenos contemporâneos, construídos historicamente. A metodologia em história de vida se apresenta como fundamental para a realização das análises. Entrar em contato, aproximar-me, dialogar e entrevistar o Roberson, a Marie e o Bernadel foi de uma grandiosidade inigualável. O acesso as suas lembranças, aos seus contatos familiares, sua infância, namoros, experiências interessantes e desesperadoras do momento de deixar o Haiti, da jornada ao desconhecido e da socialização no Brasil, tornaram possível aproximar-me de maneira completa, e também sensível, aquilo que envolve cada experiência de mobilidade contemporânea de maneira singular e também o que corresponde as migrações coletivamente. 
Os debates realizados neste trabalho são o resultado de uma caminhada de pesquisa que não finaliza nessas considerações. As lembranças narradas disponibilizaram um grande campo de pesquisa, sendo debatidos aqui brevemente aqueles que mais se destacaram considerando a caminhada realizada. Os estudos que envolvem o fenômeno de mobilidade contemporânea, os aspectos sociais haitianos, a diáspora e a presença haitiana no Brasil e no mundo, é um universo em movimento, que não cessa de renovar suas características e consequentemente, suas compreensões.

Registro as lembranças e trajetórias de três pessoas que passaram e passam por transformações em suas vidas, de país, de cidade, de amizades, de língua. No momento em que esta pesquisa foi finalizada, Roberson estava em Chapecó, Bernadel em Xanxerê e Marie nos Estados Unidos. Evidenciar suas memórias e narrativas objetiva demonstrar a experiência de mobilidade haitiana contemporânea pelos sujeitos que estão em mobilidade e que fazem parte, neste momento, da sociedade e história brasileiras, assim como dos outros locais por onde passam.

Busquei demonstrar as dificuldades enfrentadas no processo de mobilidade, bem como as situações vivenciadas pelos haitianos no oeste catarinense - de modo significativo, o preconceito evidenciado pelos estigmas e construções sociais baseadas em nacionalidade, língua e, principalmente, cor de pele -, no intuito de possibilitar uma ponte entre o universo haitiano e o brasileiro, que se encontra em socialização e integração.

\section{Referências}

ALBERTI, Verena. Manual de História Oral. 3. ed. Rio de Janeiro: Fgv, 2005.

ANDREOLA, Neuri José. Os Brasileiros e os Estrangeiros: as relações de sociabilidade entre o grupo de brancos e o grupo de negros "em um bairro de Chapecó". 2015. 73 f. TCC (Graduação) - Curso de Ciências Sociais, Universidade Federal da Fronteira Sul, Chapecó Sc, 2015.

BERNADEL, Louis Sainne. Entrevista concedida à Taíse Staudt. Xanxerê, 2018. Gravada. Transcrita.

BRASIL. Conselho Nacional de Imigração. Resolução Normativa CNIg no 97 de 12/01/2012. Dispõe sobre a concessão do visto permanente previsto no art. 16 da Lei no 6.815, de 19 de agosto de 1980, a nacionais do Haiti. Diário Oficial da União. Brasília, DF, 13 jan. 2012. Disponível em:

<https://www.diariodasleis.com.br/busca/exibelink.php?numlink=225206 >. Acesso em: 11 mar. 2018.

CÉSAIRE. Aimé. Discurso sobre o colonialismo. Anísio Garcez (trad.). Florianópolis: 
Letras Contemporâneas, 2010, 1a reimpressão.

SCHWARCZ, Lilia Moritz. O espetáculo das raças: cientistas, instituições e questão racial no Brasil 1870 - 1930. São Paulo: Companhia das Letras, 1993.

COSTA, Debora Cristina. Constituição identitária no espaço entre-línguas: marcas discursivas em narrativas de imigrantes haitianos. 2016. 106 f. Dissertação (Mestrado) Curso de Estudos Linguísticos, Universidade Federal da Fronteira Sul, Chapecó, 2016.

DAMIS, Roberson. Entrevista concedida à Taíse Staudt. Chapecó, 2017. Gravada. Transcrita.

DIVERS, Marie Merlande. Entrevista concedida à Taíse Staudt via videoconferência de Porto Príncipe, Haiti. Chapecó, 2018. Gravada. Transcrita.

FANON, Frantz. Pele negra, máscaras brancas. Salvador: Edufba, 2008. 194 p.

HALL, Stuart. A Identidade Cultural na Pós-Modernidade. Rio de Janeiro: Lamparina. 2015.

Da Diáspora: Identidades e mediações culturais. Belo Horizonte:

Editora Ufmg, 2003.

HANDERSON, Joseph. Diaspora. As dinâmicas da mobilidade haitiana no Brasil, no Suriname e na Guiana Francesa. 2015. 430 f. Tese (Doutorado) - Curso de Antropologia Social, Museu Nacional, Universidade Federal do Rio de Janeiro, Rio de Janeiro, 2015.

Vodu no Haiti- Candomblé no Brasil: Identidades culturais e sistemas religiosos como concepção de mundo afro-latino-americano. 2010. 183 f. Dissertação (Mestrado) - Curso de Ciências Sociais, Universidade Federal de Pelotas, Pelotas, 2010.

JOSEPH, Rose-Myrlie; HANDERSON, Joseph. As Relações de Gênero, de Classe e de Raça: mulheres migrantes haitianas na França e no Brasil. Revista de Estudos e Pesquisas Sobre As Américas, Brasília - DF, v. 9, n. 2, p.1-33, 11 dez. 2015. Anual.

LAFERRIÈRE, Dany. País sem chapéu. São Paulo: 34, 2011. 240 p. Tradução e posfácio de Heloisa Moreira.

MAGALHÃES, Luís Felipe Aires.O Haiti é Aqui: Análise das informações preliminares sobre os imigrantes haitianos em Santa Catarina - Brasil. In: VI Congresso da Associação Latino-Americana de população, 6., 2014, Lima- Peru. Lima - Peru, 2014. 28 p.

MARQUES, Pâmela Marconatto. Outras Estórias Haitianas: educação, resistência e esperança no mais desconhecido dos países latino-americanos. Rebela: Revista brasileira de estudos latino-americanos, Florianópolis, v. 2, n. 1, p.99-112, jun. 2012. Disponível em: <https://rebela.emnuvens.com.br/pc/article/download/85/156>. Acesso em: 01 abr. 2018.

MATIJASCIC, Vanessa Braga. Haiti: Uma história de instabilidade política. Anais do XX Encontro Regional de História: História e Liberdade, Franca, p.1-16, set. 2010. Anual. 
Disponível em:

$<$ https://www.anpuhsp.org.br/sp/downloads/CD\%20XX\%20Encontro/PDF/Autores\%20e\%2 0Artigos/Vanessa\%20Braga\%20Matijascic.pdf>. Acesso em: 22/03/2018.

PIERRE, Jean Gardy Jean. Haiti, uma República do Vodu?: Uma análise do lugar do Vodu na sociedade haitiana à luz da Constituição de 1987 e do Decreto de 2003. 2009. $144 \mathrm{f}$.

Dissertação (Mestrado) - Curso de Ciências da Religião, Pontifícia Universidade Católica de São Paulo, São Paulo, 2009.

SER imigrante e negra no sul do Brasil.. Direção de Gerliane Mendes. Chapecó: Neabi: Núcleo de Estudos Afrobrasileiros e Indígenas, 2017. Son., color. Disponível em:

<https://www.youtube.com/watch?v=3bDrSEZgtvw\&t=297s $>$. Acesso em: 9 mar. 2018.

STAUDT, Taíse. Sou diáspora: Identidade e mobilidade nas memórias de haitianos no Brasil. 2018. 141 f. TCC (Graduação) - Curso de História, Universidade Federal da Fronteira Sul, Chapecó, 2018. Disponível em: 〈https://rd.uffs.edu.br/handle/prefix/2070〉. Acesso em: 25 ago. 2018.

SOARES, Claudete Gomes; ANDREOLA, Neuri José. Integração de imigrantes haitianos no oeste catarinense: raça e relações de poder no Brasil não mestiço. In: COPENE SUL 3, 2017, Florianópolis. Anais 2017. Florianópolis: Ufsc, 2017. p. 161 - 171. Disponível em: <http://www.copenesul.com.br/ANAISCOPENESUL2017.pdf>. Acesso em: 01 maio 2018. 